\title{
Formation and Control Technology of Top Burr in Micro-Milling
}

\author{
Zhiyang Zhang, Zhenjian Yuan and Guicheng Wang \\ School of Mechanical Engineering, Jiangsu University, Zhenjiang, China
}

\begin{abstract}
Burr formed during micro-milling slot has the most direct effect on surface quality and dimension accuracy of work-piece. Compared with other positional burrs, top burrs having the biggest dimension make the subsequent de-burring operation more difficult. To analyze the effect of spindle speed, cutting depth, feeding per teeth and blade radius on top burr size, Al6061-T6, used as research object, was conducted on a 5-axis machining center with the single factor method. Effect regularities of the process parameters on burr dimension were preliminarily revealed, active control of burr dimension during micro milling operation could be possible on the basis of the experiment.
\end{abstract}

\section{Introduction}

Burr is a special phenomenon during metal cutting process, it always occurs at corners and edges of the machined parts. Most of traditional and non-traditional manufacturing process generate burrs and the de-burring process is considered to be time consuming and non-productive. Because the burrs may reduce the fit of components and can be the source of small particles during information storage hardwire assembly, thus it is inevitable to add de-burring process [1]. Gillespie[2] pointed that de-burring and edge finishing on precision components may constitute as much as 30 percent of the outlay of the finished work-pieces. For the reason of critical cutting depth and size effect, burr dimension and processing feature size are relatively close to each other, and it makes subsequent de-burring operation more difficult. Mechanical engineering experts and scholars at home and abroad have studied burr formation mechanism and control technology, made a number of research results and promoted the development of the less burr processing technology. Gillespie[3] is one of the first experts to depict and classify burr types as follows: passion burr, rollover burr, tear burr and cut-off burr. He also provided valuable references for further study. Narayanaswami[4,5]proposed a new algorithm to minimize burr formation during face milling of arbitrarily shaped polygons and their simulation records showed that cutter position, cutter radius, and work-piece orientation could be changed for primary burr. Biermann[6] conducted micro-milling experiments on austenitic stainless steel $\mathrm{X} 5 \mathrm{CrNi18}-10$, studied the action law of cutting parameters, tool geometry, lubrication mode, etc.. It was revealed that these factors had significant affection on top burr size. Toropov[7] researched the mechanism of consecutive and intermittent burr in micro-milling and feeding direction burr was the focus of attention. A useful forecasting model was set up for burr dimension and its forming process. Compared with the turning experiment of Al6061-T6, the maximum prediction error was up to $30 \%$. Le[8] explored burr phenomena in micro-cutting and the cutting direction -side burr-of prism pattern, cutting direction -exit burr -of pyramid patter were introduced. They proposed the predicting model for burr size in each case. Lee[9] carried out a study on micro burr formation and proposed a method to minimize burr size through process control in micro milling process with end mills. The results revealed that cutting speed, cutting edge radius and feed per teeth had impact on top burrs formation to some extend. Ravi[10]presented their experimental records aiming to investigate the influence of main cutting parameters on the formation of various burrs types. They also proposed an analytical model for exit burr height, which was based on burr formation geometry and the principle of continuity of work at the critical position nearing to the end of work-piece. Liu[11] established a mathematical model for calculating uncut thickness and describing the dynamic behaviors of micro milling forces components, with influences of tool wear, edge plowing and critical uncut thickness included. Their experimental records showed that a small feeding speed and tool material not prone to stick to work-piece were desirable. Thepsonthi[12]obtained optimum cutting parameters with the aim of minimizing the burr dimension and surface roughness. Their experimental model was developed with statistically methods utilized in multi objective particle swarm optimization. Meanwhile, it was noticeable that factors ignored on macro scale showed significance in micro milling operation. e. g. vibration, micro structure and deflection.

The above literatures carried out burr researches from various aspects. While, as for the problem about how cutting parameters influence top burr size, there is yet no 
uniform and clear conclusions. It is necessary to further work on the topic. Analyzing the terms of influence, revealing the rules, making reasonable choices of parameters and planning edge path, the purpose of active control and reduction of burr dimension could be successfully achieved, maximization of economic be benefitted.

\section{Experimental procedure}

Micro-slot milling experiment of Al6061-T6 was conducted on a high speed 5-axis machining centre MIKRON CUP800. Maximum spindle speed up to $20000 \mathrm{r} / \mathrm{min}$, repeating position accuracy $3 \mu \mathrm{m}$ for $\mathrm{X}$ and $\mathrm{Y}$ respectively. Choosing fine grained cemented carbide as tool material, standard type GM-2ES-D0.5, spiral angle $30^{\circ}$, rake angle $10^{\circ}$, lag angle $5^{\circ}$, blade dimension $0.5 \mathrm{~mm}$ in diameter with various blade arc radius. In order to avoid introducing disturbance to experimental results by surface oxide layer, finishing milling of top surface was done in advance. Measuring instrument OLYMPUS DSX500 optical microscope. Taking vibration into consideration, causing top burr size to be metabolic, selecting the mean values in stable machining condition as measured records, Figure. 1 and Figure. 2 are micro-milling tools with various blade radius and measuring apparatus and equipment used in the experiment.
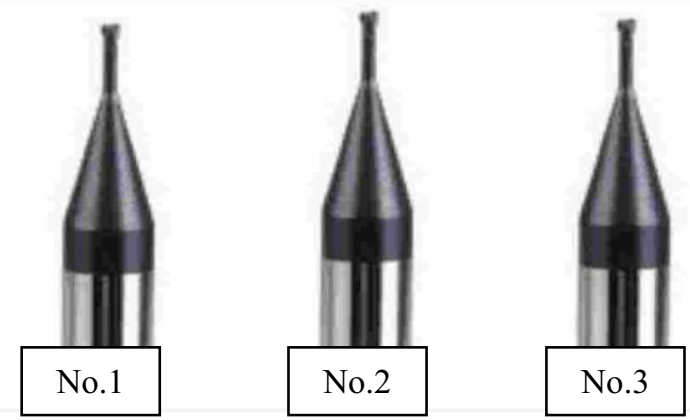

Figure. 1. Micro-milling tools with various blade arc radius

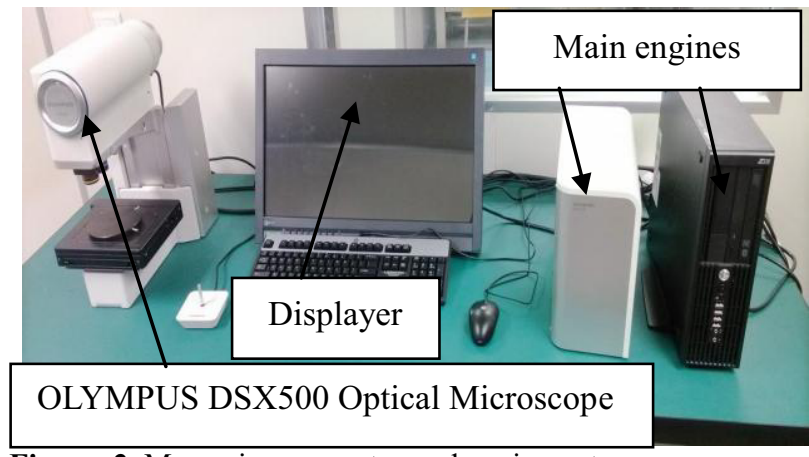

Figure. 2. Measuring apparatus and equipment

Firstly, setting up a group of benchmark parameters, using single factor method to analyze the changing attributes of top burr height along with different factors combination. Parameters are as follows in Table 1.

Table 1. Setting of cutting parameters.

\begin{tabular}{c|c|}
\hline $\begin{array}{c}\text { Spindle } \\
\text { Speed(r/min })\end{array}$ & $7500,8500,9500,10500,11500,12500$ \\
\hline
\end{tabular}

\begin{tabular}{|c|c|}
\hline $\begin{array}{c}\text { Feeding } \\
\text { speed }(\mu \mathrm{m} / \mathrm{z})\end{array}$ & $0.5,1,1.5,2.0,3.0,4.0$ \\
\hline $\begin{array}{c}\text { Cutting } \\
\text { Depth }(\mu \mathrm{m})\end{array}$ & $30,40,50,60,70,80$ \\
\hline $\begin{array}{c}\text { Benchmark } \\
\text { Value }\end{array}$ & $10500 \mathrm{r} / \mathrm{min}, 4.0 \mu \mathrm{m} / \mathrm{z}, 40 \mu \mathrm{m}$ \\
\hline
\end{tabular}

\section{Results and discussion}

Work-piece was presented in Figure. 3 and micrographs of top burrs were shown in Figure. 4, respectively.

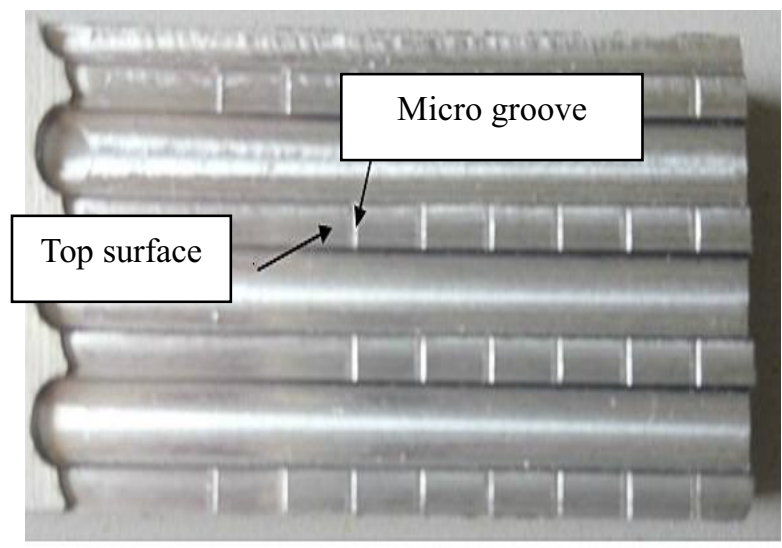

Figure. 3. Work-piece after micro-milling

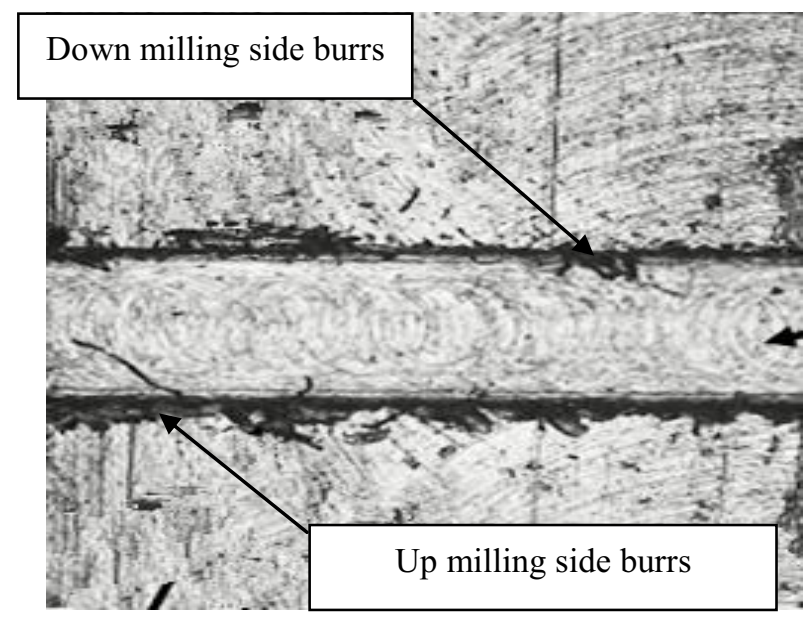

Figure. 4. Micrograph of top burrs

\subsection{Effect of spindle speed on top burr size}

Variation tendency of top burr dimension with mutative spindle speeds, fixed cutting depth $40 \mu \mathrm{m}$ and feed per teeth $4 \mu \mathrm{m}$, is shown in Figure. 5.

From Figure. 5, it can be seen that the whole dimensions present rising trend, along with gradually incremental spindle speeds. From $7500 \mathrm{r} / \mathrm{min}$ to $10500 \mathrm{r} / \mathrm{min}$, increasing trend-line is not obvious. The main reasons may be that increasing cutting speed solely leads to more material removal rate in the same time. Because crumb slot is very limited owing to its physical dimension. If the removed material can not be timely discharged, it will be pushed to top surface along up and down milling sides automatically and top burrs emerge on 
the work-piece. In the meantime, increased speed will quicken the deformation of the removed materials, accordingly contacting time between tool and work-piece be decreased, bring milling force to lower degree and eventually lead to smaller burrs, so the trend-line will be explained by the synthetic action. Further, with speed continuing to augment, material removal rate increases rapidly and gradually takes a dominant position during the machining process, leading the top burrs to increase in dimension significantly.

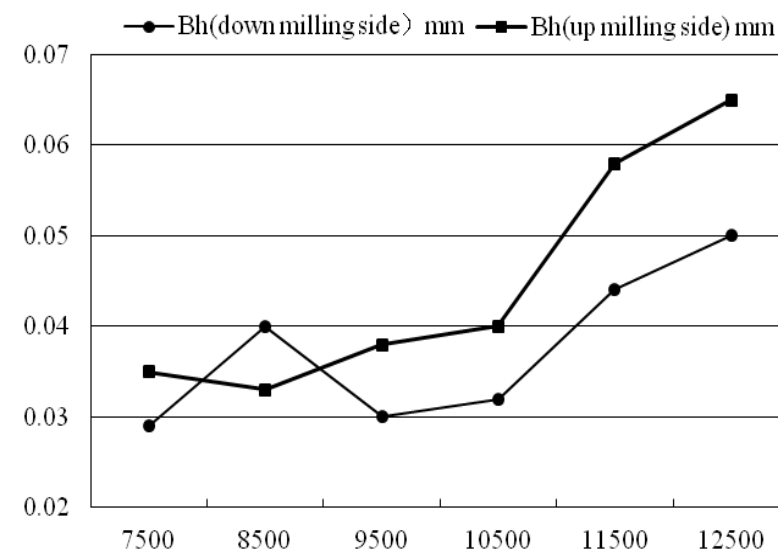

Figure. 5. Effect of spindle speed on top burrs

\subsection{Effect of feeding speed on top burr size}

On condition that spindle speed 10500r/min, milling depth $40 \mu \mathrm{m}$, the trend-chart of top burr height along with feeding speed is described in Figure. 6.

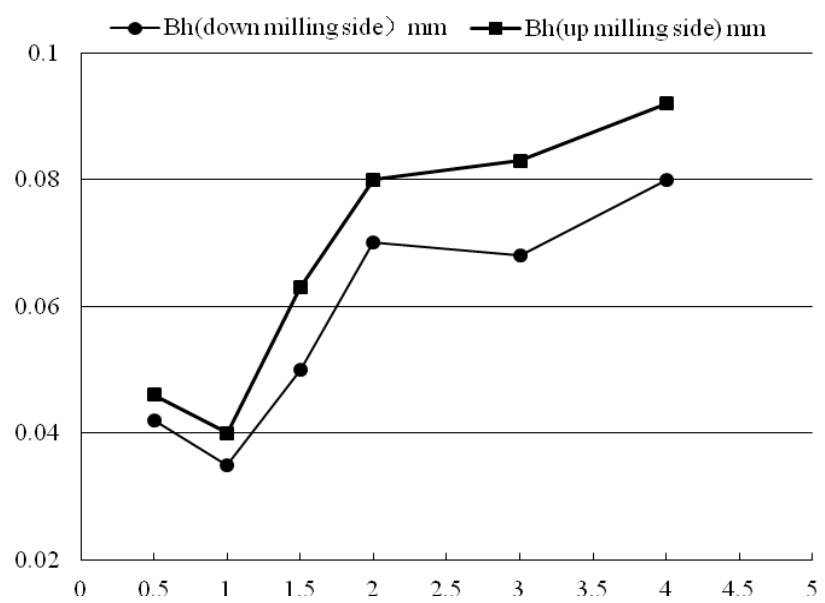

Figure. 6. Effect of feeding speed on top burrs

According to Figure. 6, the conclusion drawn is that when taking minimum value, milling thickness is near to critical layer, cutting and ploughing can act on material simultaneously in this case. Cutting layers flow onwards by forward extrusion of cutter blade and accumulate on rake face, eventually larger burr will not be avoided. Exceeding critical thickness, plow effect will no longer play a leading role and smaller dimension could be obtained. Meanwhile, with feeding speed constantly rising, thickness of burr is bound to have large augmenter as shown in above Figure. 6, resulting in jumbo size.
What is more, edge wear could not be ignored, burr dimension presents increasing tendency accompanying with plough action.

\subsection{Effect of depth of cut on top burr size}

As shown in Figure.7, the trend-line of burr size continues to rise with changing cutting depth, on condition that feed per teeth $4 \mu \mathrm{m}$, rotating speed $10500 \mathrm{r} / \mathrm{min}$, respectively.

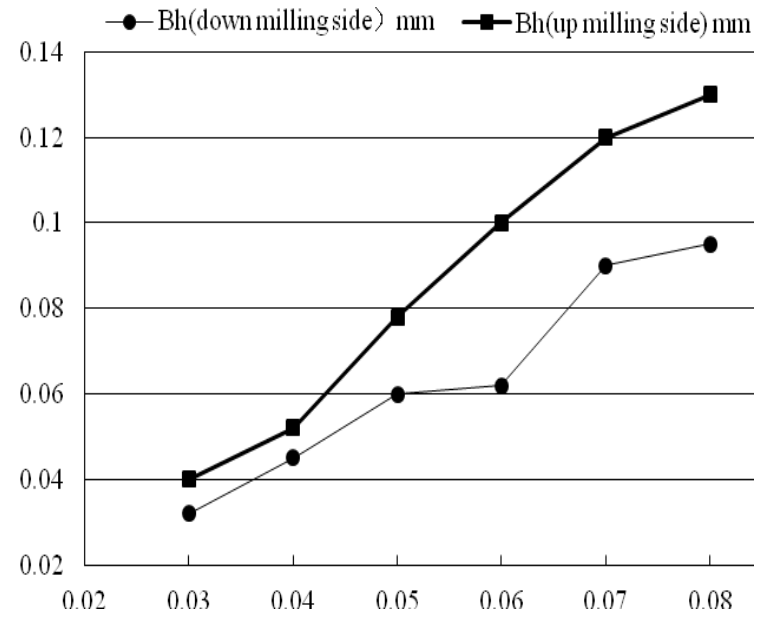

Figure. 7. Effect of depth of cut on top burrs

It is obvious that top burr size is more sensitive to axial milling depth. Increased depth contributes to much volume of removed material at the same time, contacting area between blade and work-piece rises to certain degree, and thus it makes friction force become larger, exacerbate tooth wear accordingly causing size effect to take a position that can not be ignored during micro-milling process. However, owing to its physical dimension, crumb slot can not hold so many scraps and remained chips may be crushed by subsequent ones not having absolute deformation. In the case of integrated effect of multiple factors, curly burrs can be formed. At the same time, along with the machining process, tool blade is bound to be obtuse, and it becomes easy to understand the phenomenon that down milling burr size is much smaller than up milling. It also can promulgate the fact that top burr dimension shows sensitive to degree of tool sharpness.

\subsection{Effect of blade arc radius on top burr size}

Compared with conventional milling process, edge wear quantity, feed per teeth and axial depth are roughly in the same order of magnitude. Edge radius of circular arc not only has significant impaction on surface quality and dimensional accuracy, but also on burr size.

Optical microscopic of three milling tools with different abrasion loss and corresponding micro-groove are presented in Figure. 8. Parameters employed in this case are as follows: spindle speed $10500 \mathrm{r} / \mathrm{min}$, feed per teeth $4 \mu \mathrm{m}$ and axial depth $40 \mu \mathrm{m}$, respectively.

Figure.8 (a), (c), (e) represent tools No.1, No.2 and No.3, respectively. The abrasion loss increase in turn. According to Figure. 8 (b), (d), (f), it is obvious that 
significant differentiation emerges among top burr sizes and types. The first tool has the most sharp edge and corresponding burrs have the smallest dimension and uniform distribution along two edges machined. No.2, owning a mild degree of abrasion loss of blade, makes the homologous burr dimension being large than the former distinctly. It is noted that the last has maximum dimensions and deteriorative shapes on top surface, thus resulting in much obstacle to subsequent de-burring operation.


Figure. 8. Micro graphs of wearing edges and corresponding top burrs

\section{Conclusion}

Impactions of spindle speed, feeding per teeth, cutting depth and circular arc radius on micro-slot milling top burr size are investigated using single factor method. According to experimental results, the following conclusions are drawn:

(1) Among range of $7500 \mathrm{r} / \mathrm{min}$ to $10500 \mathrm{r} / \mathrm{min}$, burr dimension lightly increased. When beyond 10500r/min, increasing trend-line is very obvious. It is worth noting that there is critical speed value leading to the smallest burr dimension.

(2) Generally speaking, with the augment of feeding speed, burr height shows an accessorial trend. There is a critical feeding value $1 \mu \mathrm{m} / \mathrm{z}$, which results in minimum dimension. Augmenter is apparent and significant.

(3) Influence of milling depth on burr size is more obvious. The dimension continues to rise linearly. On the satisfaction of production efficiency condition, in order to achieve the purpose of active control of burr size, choosing small milling depth is sensible.

(4) Top burr is susceptive on abrasion loss. With the increase of abrasion, burr size becomes larger and shape more scrambled.

In view of the limitations of the experimental conditions, high speed micro milling of aluminum alloy Al6061 - T6 was conducted diminutively. In order to guarantee the rationality of the results, it is of great significance to further expand the research scopes.

In subsequent research and analysis, it is consumingly recommended that more influential factors, such as types of tested materials, selection ranges of cutting process parameters, different kinds of tool materials and coating types, be taken into elaborative consideration. Moreover, machine tools vibration, work-piece excision angle and cutting tools geometry during micro milling, may also be influential factors on the response values, that is to say burr dimension and types.

At the same time, it is strongly suggested to explore other schemes to carry out micro milling experiments, e.g. orthogonal test which is widely used in scientific research. It is noticeable that other interesting methods, for instance, response surface, analysis of variance and multiple targets optimization, can also be utilized to further study the experimental records. Finally, the influence laws of cutting process parameters on different position burrs, micro milling force components and surface roughness, are also train of thought.

In conclusion, in order to achieve the goal of higher productivity, dimensional precision and surface quality simultaneously, micro milling cutting process parameters with optimum combinations and reasonable scientific analysis methods, should be taken into consideration scrupulously.

\section{Acknowledgement}

This research is based upon work by the NNSF of China (Grant No.51075192) and National key projects of P. R. China (Grant 2013ZX04009031).

\section{References}

1. S.L. Ko, D.A. Dornfel, A Study on Burr Formation Mechanism, J. ENG. MATER, 113, pp.75-87, 1991.

2. 2. L.K. Gillespie, De-burring and Edge Finishing Handbook ( SME, New York, 1999).

3. L.K. Gillespie, The formation and properties of machining burrs, J. Manuf. Sci. E., 98, 
pp.66-74,1976.

4. R. Narayanaswami, D. Dornfeld, Burr minimization in face milling: a geometric approach, Trans ASME, J. Eng. Ind., 119, pp. 170-177.

5. R. Narayanaswami, D. Dornfeld, Design and process planning strategies for burr minimization and deburring. Trans. NAMRi/SEM, 22, pp.313, 1994.

6. D. Biermann, M. Steiner, Analysis of micro burr formation in austenitic stainless steel X5CrNi18-10, Procedia CIRP. 3, pp.97-102, 2012.

7. A. Toropov, L.K. Sung, A model of burr formation in the feed direction in turning, Int. J. Mach. Tool. Manu., 46, pp.1913-1920, 2006.

8. D. Le, J.M. Lee, S.J. Kim, et al., Burr analysis in micro-grooving, Int. J. Adv. Manuf. Tech. 50, pp.569-577, 2010.

9. K. Lee, D.A. Dornfeld, An experimental study on burr formation in micro milling aluminium and copper, Trans NAMRI/SME, 30, pp.255-262, 2002.

10. L. Ravi, B. Vivek, K.S. Ramesh and S.S. Joshi, Characterization and modeling of burr formation in micro-end milling, PRECIS. ENG., 35, pp.625-637, 2011.

11. H. Liu, Y. Sun, Y. Geng and D. Shan, Experimental research of milling force and surface quality for TC4 titanium alloy of micro-milling, Int. J. Adv. Manuf. Technol., 79, pp.705-716, 2015.

12. T. Thepsonthi, T. Özel, Multi-objective process optimization for micro-end milling of Ti-6Al-4V titanium alloy, Int. J. Adv. Manuf. Technol., 63, pp.903-914, 2012. 